Научная статья

УДК 37.018.43

DOI: $10.18101 / 2307-3330-2021-2-61-64$

\title{
КРЕАТИВНОСТЬ В КОНТЕКСТЕ ДИСТАНЦИОННОГО ОБУЧЕНИЯ
}

\author{
(C) Парфенова Анастасия Владимировна \\ педагог-психолог, \\ Центр диагностики и консультирования г. Улан-Удэ \\ Россия, 670034, г. Улан-Удэ, ул. Хахалова, 8 \\ parfenovanasty82@gmail.com
}

\begin{abstract}
Аннотация. В статье представлены результаты эмпирического исследования отношений студентов высших учебных заведений к дистанционному формату обучения в целом, а также в контексте уровней сформированности у них вербальной креативности с такими ее критериями, как вербальная беглость и вербальная оригинальность. Обобщенные в материалах результаты исследования свидетельствуют о том, что большинство респондентов в целом удовлетворены процессом обучения, находят в ней как положительные аспекты, так ряд трудностей дистанционной формы обучения. Определенный эмпирический интерес представляет выявленный факт, что в группах студентов с нормальным и высоким уровнем развития вербальной креативности существенные различия отсутствуют и отмечаются только в ответах на открытые вопросы, например, относительно того, чтобы хотели изменить в проведении дистанционного обучения.

Ключевые слова: отношение к дистанционному обучению, вербальная креативность, анкетирование, тест Е. Торренса, студенты, учебная мотивация, самообразование, интеллектуальная энергия.
\end{abstract}

\section{Для цитирования}

Парфенова А. В. Креативность в контексте дистанционного обучения // Вестник Бурятского государственного университета. Образование. Личность. Общество. 2021. № 2. C. 61-64.

Введение системы дистанционного обучения в практику жизни первоначально вызывало множество объективных затруднений и негативных эмоциональных переживаний у участников образовательного процесса, предъявляя повышенные требования к навыкам владения новыми технологиями и личностным ресурсам человека. Возрастают требования не только к интеллектуальным способностям, но все больше говорят о развитии креативности личности, как необходимой характеристике успешно адаптированного человека. Понятие креативности неоднозначно и вызывает множество споров, даже общепринятого определения данного понятия не существует. В широком значении креативность фактически отождествляют с творчеством, в узком значении ее можно свести к дивергентным способностям [2].

Целью эмпирического исследования является выявить отношение студентов к дистанционному обучению, а также проследить существуют ли какие-либо особенности отношения студентов к дистанционной форме обучения в зависимости от уровня развития вербальной креативности. 
В марте-апреле 2021 г. нами было проведено исследование, в котором приняли участие 64 студента высших учебных заведений. Средний возраст выборки составил 17 лет, участвовали студенты 1-2-х курсов высших учебных заведений г. Улан-Удэ.

Вполне закономерным является то, что студенты отмечают, что с распространением дистанционного обучения время, проведенное у экрана электронного устройства, увеличилось, в среднем по выборке оно равно 6,5 ч. Также $28 \%$ респондентов используют при дистанционном обучении только телефон и считают это удобным и приемлемым, половина респондентов пользуется во время дистанционного обучения телефоном и другим устройством. Только $22 \%$ обычно использует при дистанционном обучении персональный компьютер или ноутбук.

Проведенный опрос показал, что в целом большинство студентов считают, что успешно адаптировались к дистанционному формату (87,5\% опрошенных). Около половины респондентов $(51,6 \%)$ отметили, что их уровень мотивации с введением дистанционного формата обучения не изменился, $23 \%$ - увеличился, $20 \%$ - уменьшился.

Таким образом, большинство респондентов в целом удовлетворены процессом обучения, хотя, конечно же, отмечают ряд трудностей дистанционной формы обучения. Среди них большинство респондентов отмечали сложность выполнения практических заданий (31\%), увеличение объема тематической информации (34\%), плохое качество интернет-соединения (47\%). В представленной выборке только один респондент отметил вариант «недостаточное владение компьютерными технологиями», что указывает на то, что большинство студентов считают свои навыки владения компьютерными технологиями удовлетворительными.

Часть респондентов (5\%) отмечает, что не видят никаких преимуществ в дистанционном обучении и отрицательно относятся к использованию дистанционных технологий. Остальные студенты отмечают некоторые преимущества данной формы обучения: «гибкость учебного процесса» (72\%), «обучение в комфортной и привычной обстановке» $(75 \%)$, «использование современных технологий обучения» $(25 \%)$, «доступность содержания материала для скачивания, возможность повторно посмотреть видеозаписи» (28\%), «индивидуальный темп обучения» (23\%), кроме того, респонденты считают, что дистанционное обучение способствует формированию навыков работы с большим объемом информации $(67 \%)$, развивает навыки самоконтроля (58\%), формирует мотивацию к самообразованию (44\%). Следует отметить, что большинство студентов не считают, что дистанционное обучение способствует получению практических навыков и повышению качества обучения (98\%).

Опрос показывает, что 70\% респондентов оценивают обучение в дистанционном формате в качестве дополнительного, $75 \%$ - готовы продолжить обучение в будущем в смешанной форме (очной и дистанционной). Меньший процент респондентов предпочитает дистанционный формат в качестве основной формы обучения (11\%).

Во время обучения в дистанционном формате в группе опрашиваемых студентов несколько изменилось распределение времени. Так, до дистанционного обучения игровому контенту уделяли внимание $33 \%$ респондентов, после пере- 
вода на дистанционный формат $-22 \%$. Закономерно возросло количество студентов, которые уделяют больше времени контенту, связанному с обучением (с 34 до 53\%). Практически не изменилось время, уделяемое развлекательному контенту (по 23\%), и контенту, связанному с общением (59 и 56\%).

Таким образом, опрос показывает, что в целом студенты адаптированы к системе дистанционного обучения, большинство находят в ней некоторые положительные аспекты, но рассматривают ее в основном в качестве вспомогательного варианта, выбирая в качестве предпочтительной смешанную форму обучения.

Анализ результатов по тесту Е. Торренса показал, что у $88 \%$ исследуемых уровень значения общей вербальной креативности относится к норме, низких значений в данной выборке не выявлено. Показатель «вербальная креативность» стабильно и надежно отражает общую креативную энергию личности [1]. Общая вербальная креативность складывается из показателей «вербальная беглость», «вербальная гибкость» и «вербальная оригинальность». Высокий уровень развития «вербальной беглости» диагностируется у $8 \%$ респондентов, это отражает их способность предлагать большое количество идей в вербальной форме. Значения выше нормы по показателю «вербальная гибкость» отмечаются у 8\% студентов, что, на наш взгляд, может быть следствием достаточной интеллектуальной энергии или высокой мотивации, также это указывает на способность предлагать разнообразные идеи, подходить к проблеме с разных сторон, использовать различные стратегии решения. Высокий уровень развития вербальной оригинальности выявлен у $12 \%$ респондентов. Показатель «вербальная оригинальность» отражает способность человека предлагать идеи, отличные от очевидных, общепринятых и банальных. Фактически оригинальные решения требуют способности воздерживаться от выдвижения первого пришедшего в голову ответа, который, как правило, бывает простым и стандартным. Люди, имеющие высокий балл по оригинальности, как правило, обладают большим запасом интеллектуальной энергии и в определенной степени являются нонконформистами.

Анализ ответов опроса об отношении к дистанционному обучению показал, что в группах студентов с нормальным и высоким уровнем развития вербальной креативности существенные различия отсутствуют и отмечаются только в ответах на открытые вопросы. Так, около $20 \%$ испытуемых ответили в анкете на открытый вопрос о пожеланиях к проведению дистанционного обучения в будущем. Интересным с нашей точки зрения является то, что студенты с высокими баллами по тем или иным показателям вербальной креативности входили в группу «отвечающих», высказывали свое мнение.

В качестве пожеланий и замечаний чаще всего встречались ответы о необходимости более качественной и понятной обратной связи от педагога, четкой системы требований, более понятного тематического контента, оптимизации количества материала, снижении нагрузки, выбора электронных площадок, а также жалобах на качество интернет-соединения.

Интересным с нашей точки зрения является то, что студенты с высокими баллами по показателям «вербальной беглости» и «вербальной оригинальности» высказали оригинальные, единично встречаемые в выборке пожелания к дистанционному обучению. В частности, были высказаны предложения к организации и характеру проведения дистанционных занятий, а также включения в процесс 
дистанционного обучения более современных электронных программ и технических средств. Очевидным является, что осуществление этих пожеланий не всегда и не везде возможно по объективным причинам, что признается и самими студентами. Выявленный факт свидетельствует о том, что креативности личности студента можно рассматривать как ресурс для развития и усовершенствования системы дистанционного образования.

Следует отметить, что добровольность участия также отражает специфику выборки, так как косвенно свидетельствует об определенном отношении к теме исследования, о заинтересованности его участников. Поэтому мы считаем необходимым уточнить результаты исследования на более обширной выборке, включив в рассмотрение дополнительные личностные параметры.

Лuтература

1. Туник Е. Е. Тест Е. Торренса. Диагностика креативности: методическое руководство. Санкт-Петербург: ИМАТОН, 1998. 170 с. Текст: непосредственный.

2. Холодная М. А. Психология интеллекта. Парадоксы исследования. СанктПетербург, 2002. 208 с. Текст: непосредственный.

Статья поступила в редакиию 05.06.2021; одобрена после рецензирования 05.07.2021; принята к публикаџии 29.11.2021.

\section{CREATIVITY IN THE CONTEXT OF DISTANCE LEARNING}

Anastasiya V. Parfyonova

Educational Psychologist,

Ulan-Ude Diagnostic and Consultation Center

8 Khakhalova St., Ulan-Ude 670034 Russia

parfenovanasty82@gmail.com

Abstract. The article presents the results of an empirical study of the attitude of students of higher educational institutions to the distance learning in the context of the levels of development of their verbal creativity, in particular, such criteria as verbal fluency and verbal originality. The results of the study have shown that the majority of respondents are relatively satisfied with the learning process, they identify both the positive aspects and a number of difficulties in distance learning. It has been revealed that there are no significant differences in the answers of students with a normal and high level of verbal creativity development, they are noted only in the answers to open questions, for example: "What do you want to change in the organization of distance learning?”.

Keywords: attitude to distance learning, verbal creativity, questionnaires, Torrance tests, students, learning motivation, self-education, intellectual energy.

\section{For citation}

Parfyonova A. V. Creativity in the Context of Distance Learning. Education. Person. Society. 2021; 2: 61-64 (In Russ.).

The article was submitted 05.06.2021; approved after reviewing 05.07.2021; accepted for publication 29.11.2021. 